\title{
Nephrotic Syndrome: Updates and Approaches to Treatment
}

\section{Michelle N Rheault, MD}

\author{
Address \\ Division of Pediatric Nephrology, University of Minnesota Masonic Children's \\ Hospital, 2450 Riverside Ave, MB680, Minneapolis, MN, 55454, USA \\ Email: rheau002@umn.edu
}

Published online: 18 March 2016

(C) Springer International Publishing AG 2016

This article is part of the Topical Collection on Pediatric Nephrology

Keywords Minimal change disease - Focal segmental glomerulosclerosis - Corticosteroid - Cyclosporine - Tacrolimus • Rituximab · Mycophenolate mofetil · Proteinuria

\section{Opinion statement}

Nephrotic syndrome (NS) is among the most common pediatric kidney diseases with a high risk of morbidity and mortality due to infection and thrombosis. Goals of treatment are to reduce proteinuria to normal levels thereby reducing symptoms and risk of complications. Children with NS should initially be treated with prednisone or prednisolone at a dose of $60 \mathrm{mg} / \mathrm{m}^{2} /$ day daily for 6 weeks followed by $40 \mathrm{mg} / \mathrm{m}^{2} /$ day given every other day for an additional 6 weeks. While most children are steroid responsive, approximately $20 \%$ of children with NS do not go into remission with steroids and should be treated with a calcineurin inhibitor such as cyclosporine or tacrolimus. Some children with NS who respond to steroids eventually have a frequently relapsing or steroid-dependent course and may have significant side effects from cumulative corticosteroid therapy. For these children, steroid-sparing medications are required. Treatment with mycophenolate mofetil is recommended as first-line therapy for treatment of frequently relapsing or steroiddependent NS with steroid toxicity due to its favorable side effect profile compared to alternatives. If this is not effective, alternate agents such as cyclophosphamide, calcineurin inhibitors, or rituximab could be considered after careful review of the pros and cons of each medication with the child's family. Further randomized controlled trials are necessary to determine which agents are most effective and to determine methods to predict medication response in individual children.

\section{Introduction}

Nephrotic syndrome (NS) is among the most common pediatric kidney diseases and is defined as massive proteinuria ( $>40 \mathrm{mg} / \mathrm{m}^{2} / \mathrm{h}$ or urine protein to creatinine ratio $>2 \mathrm{~g} / \mathrm{g}$ ) leading to hypoalbuminemia $(<2.5 \mathrm{~g} / \mathrm{dL})$, edema, and hyperlipidemia. The peak age at initial presentation of childhood NS is 2 years with $60-70 \%$ presenting prior to age 6 years [1]. Most children with NS are treated initially with oral corticosteroids, and they can be clinically classified based on their ability to achieve remission (i.e., complete normalization of 
proteinuria). Approximately $85 \%$ of children under the age of 6 years are steroid-sensitive, whereas the remainder have steroid-resistant disease. Older children are more likely to have steroid-resistant NS. Children with steroid-resistant disease may have an underlying genetic cause for NS, and providers should consider genetic testing in this population, depending on the age of the child [2]. While inherited causes of NS are often resistant to all therapies, there are reports of complete or partial remission in some children [3]. Further studies are required to understand the response to therapy in children with inherited NS.

For those children who respond to steroids, the majority will have one or more relapses and half will have frequently relapsing ( $\geq 4$ relapses/year) or steroid-dependent (two consecutive relapses during steroid therapy or within 14 days of stopping steroids) NS [4]. Children with frequently relapsing NS and steroid-dependent NS may have significant side effects from cumulative corticosteroid therapy so treatment with other agents is often required. Therapy for these children should be guided by a pediatric nephrologist.

Clinical NS can be the result of a number of different pathologies on kidney biopsy. Minimal change disease (MCD) is the most common histopathologic finding in children with NS [1]. Kidney biopsies from patients with MCD have a normal appearance by light microscopy with effacement of podocyte foot processes visible by electron microscopy (EM) [5]. In addition to podocyte effacement by EM, biopsy samples from children with focal segmental glomerulosclerosis (FSGS) demonstrate light microscopic findings of segmental sclerosis within some glomeruli [6]. Children with FSGS on renal biopsy are less likely to go into remission with steroids than children with MCD and are more likely to have progressive chronic kidney disease [1].

Prior to the 1950s, no treatments were available for children with nephrotic syndrome and outcomes were uniformly poor with mortality rates of up to $65 \%$ primarily due to complications of infection and thrombosis [7]. Infection remains the most common complication of NS affecting approximately $20 \%$ of hospitalized patients [8]. In addition to loss of albumin in the urine, nephrotic patients lose components of the alternative complement pathway, including factors $\mathrm{B}$ and $\mathrm{D}$ that increase their susceptibility to infection with encapsulated organisms such as Streptococcus pneumoniae [9-12]. Thromboembolism is less common, affecting $\sim 3 \%$ of children with nephrotic syndrome, but can be a catastrophic complication [13]. Children with active NS are at risk for thromboembolism for several reasons. First, there is urinary loss of factors that inhibit clot formation such as antithrombin III (ATIII). Second, there is increased production of pro-coagulant factors by the liver [14]. After successful treatment of nephrotic syndrome with corticosteroids in the 1950s and 1960s, mortality from infection and thrombosis dropped to $9 \%$, with further reductions to $<1 \%$ in the modern era with continued improvements in treatment and supportive care $[7,15]$. Thus, successfully treating nephrotic syndrome to attain a remission is important in reducing the morbidity and mortality that go along with this disease. This review will discuss treatments for steroid-sensitive NS and steroid-resistant NS. Goals of treatment are to attain remission with minimal medication side effects.

\section{Corticosteroids}

Although used universally, the mechanism of action of corticosteroids in the treatment of NS is unknown. It has been hypothesized that NS is a disorder of the immune system, with T-cell dysfunction resulting in the release of a circulating factor that causes podocyte foot process effacement and proteinuria [16]. Corticosteroids are presumed to act by suppression of a T-cell-mediated factor; however, the definitive identification of this circulating factor has remained elusive [17]. Alternately, corticosteroids may also have an effect on the podocyte directly through stabilization of the actin cytoskeleton and alteration of gene expression [18, 19].

The 2012 Kidney Disease: Improving Global Outcomes (KDIGO) clinical practice guidelines recommend initial treatment of childhood NS with either prednisone or prednisolone at a dose of $60 \mathrm{mg} / \mathrm{m}^{2} /$ day (or $2 \mathrm{mg} / \mathrm{kg} /$ day) as a single daily dose for 4-6 weeks, followed by $40 \mathrm{mg} / \mathrm{m}^{2}$ (or $1.5 \mathrm{mg} / \mathrm{kg} /$ day) every other day for $2-$ 5 months with tapering (Table 1) [20••]. The recommended daily starting dose of $60 \mathrm{mg} / \mathrm{m}^{2} /$ day was used empirically in the International Study of Kidney Disease in Children (ISKDC) in the 1960s and 1970s and adopted by the Arbeitsgemeinschaft Für Pädiatrische Nephrologie (APN) studies in the 1970s and 1980s. No randomized controlled trials have been performed to examine different initial doses of prednisone. The ISKDC treatment regimen went on to treat with daily steroids for 4 weeks followed by $40 \mathrm{mg} / \mathrm{m}^{2} /$ day for 3 consecutive days out of 7 for the following 4 weeks and found that $85 \%$ of children $<6$ years of age and $60 \%$ of children between $6-16$ years responded to this regimen [1]. Unfortunately, a high percentage of children treated 
Table 1. Recommended corticosteroid dose for children with nephrotic syndrome

\begin{tabular}{ll}
\hline Initial episode of NS & KDIGO recommendation \\
& Single daily dose of $60 \mathrm{mg} / \mathrm{m}^{2} /$ day or $2 \mathrm{mg} / \mathrm{kg} /$ day $(\max .60 \mathrm{mg})$ for 4-6 weeks \\
& Then, $40 \mathrm{mg} / \mathrm{m}^{2} /$ day or $1.5 \mathrm{mg} / \mathrm{kg} /$ day $(\mathrm{max} .40 \mathrm{mg}$ ) given every other day for $2-5$ months with tapering \\
& Minimum $12-$ week duration \\
Relapse of NS & $\begin{array}{l}\text { Single daily dose of } 60 \mathrm{mg} / \mathrm{m}^{2} / \text { day or } 2 \mathrm{mg} / \mathrm{kg} / \text { day }(\max .60 \mathrm{mg}) \text { until complete remission for } 3 \text { days } \\
\text { Then, } 40 \mathrm{mg} / \mathrm{m}^{2} / \text { day or } 1.5 \mathrm{mg} / \mathrm{kg} / \text { day }(\max .40 \mathrm{mg}) \text { given every other day for } 4 \text { weeks }\end{array}$
\end{tabular}

with this regimen have relapses of the disease, so a number of subsequent studies have been performed in an attempt to optimize the initial steroid course to minimize risk of relapse. A meta-analysis of randomized controlled trials showed that treatment with steroids for 3 months or more can decrease the risk of relapse at 12 years by $30 \%$ compared to the shorter ISKDC regimen [21]. More recent randomized placebo-controlled trials have evaluated children with NS treated with 3 vs. 6 months of steroids for their initial course and did not demonstrate differences in rates of sustained remission or frequently relapsing disease between these groups $[22 \bullet, 23]$. Finally, studies have compared the 3 consecutive days per week steroid dosing to alternate day steroid dosing and found lower 1-year relapse rates for children treated with alternate-day steroids, leading to the widespread adoption of alternate-day dosing during the steroid taper [24].

There are no randomized controlled trials examining the optimal dose or steroid treatment period for children who experience relapse. KDIGO guidelines recommend treatment with $60 \mathrm{mg} / \mathrm{m}^{2} /$ day (or $2 \mathrm{mg} / \mathrm{kg} / \mathrm{day}$ ) as a single daily dose until the urine is negative for protein for 3 days, then $40 \mathrm{mg} / \mathrm{m}^{2}$ (alternately $1.5 \mathrm{mg} /$

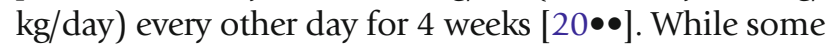
clinicians may be tempted to use this "shorter" regimen for the initial episode of nephrotic syndrome in patients, it is not recommended, as this approach leads to a significant increased risk of relapse at 2 years and therefore more cumulative steroid exposure [25]. There is wide variability among pediatricians and pediatric nephrologists in their initial approach to treatment of NS, despite various national and international consensus

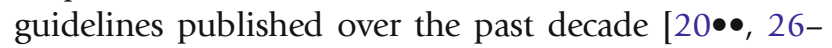
30].

Children with frequently relapsing or steroiddependent NS should be treated with alternate-day steroids for at least 3 months after entering remission at the lowest dose possible to maintain remission [20••]. Some children will require prolonged, alternate-day steroids in order to maintain remission [31].

Children with frequently relapsing NS and steroiddependent NS can have high cumulative exposure to steroids and are at risk for developing steroidassociated side effects. These can include short stature, cataracts, hyperglycemia, cushingoid appearance, obesity, hypertension, mood and sleep disorders, avascular necrosis of the hip, decreased bone density, and stomach ulcers [32]. Children receiving long-term steroids should be monitored for complications of their use, including yearly eye exams to exclude the development of cataracts. Children with frequently relapsing NS and steroid-dependent NS who develop steroid-associated side effects should be offered steroid-sparing agents (Table 2).

\section{Alkylating agents}

Alkylating agents such as cyclophosphamide and chlorambucil are alternate agents for children with frequently relapsing NS and steroid-dependent NS and can induce a sustained remission in some children. Alkylating agents are not effective for children with steroid-resistant NS [33-35]. Cyclophosphamide directly prevents cell division by cross-linking DNA strands and decreasing DNA synthesis. Its mechanism of action in NS is unknown but is presumably due to immunosuppressive effects on T-cells. Concern about risks of severe side effects such as gonadal toxicity and increased incidence of malignancy limits the current use of chlorambucil despite its historic use in children with NS [36].

Cyclophosphamide is given orally for 8-12 weeks at a dose of $2 \mathrm{mg} / \mathrm{kg} /$ day. Children should be in remission with steroids before cyclophosphamide is started, and steroids should be continued at tapering doses during cyclophosphamide therapy [33, 37]. 


\begin{tabular}{|c|c|c|}
\hline Medication & Dose & Major side effects \\
\hline Corticosteroids & Alternate day oral, lowest dose to maintain remission & $\begin{array}{l}\text { Short stature } \\
\text { Cataracts } \\
\text { Hyperglycemia/diabetes } \\
\text { Hypertension } \\
\text { Cushingoid appearance } \\
\text { Obesity } \\
\text { Mood and sleep disorders } \\
\text { Avascular necrosis of the hip } \\
\text { Decreased bone density } \\
\text { Gastritis/stomach ulcers }\end{array}$ \\
\hline Cyclophosphamide & $2 \mathrm{mg} / \mathrm{kg} /$ day orally for 8-12 weeks & $\begin{array}{l}\text { Gonadal toxicity/sterility } \\
\text { Leukopenia } \\
\text { Infection } \\
\text { Hair loss } \\
\text { Hemorrhagic cystitis } \\
\text { Malignancy } \\
\text { Teratogenic }\end{array}$ \\
\hline CNI: & 4-5 mg/kg/day orally divided twice daily & Hypertension \\
\hline Cyclosporine & $0.1 \mathrm{mg} / \mathrm{kg} /$ day orally divided twice daily & Renal toxicity \\
\hline Tacrolimus & & $\begin{array}{l}\text { Hypertrichosis } \\
\text { Gingival hypertrophy } \\
\text { Diabetes }\end{array}$ \\
\hline $\begin{array}{l}\text { Mycophenolate } \\
\text { mofetil }\end{array}$ & $600 \mathrm{mg} / \mathrm{m}^{2} /$ dose orally given twice daily & $\begin{array}{l}\text { Stomach pain } \\
\text { Diarrhea } \\
\text { Leukopenia } \\
\text { Infection } \\
\text { Teratogenic }\end{array}$ \\
\hline Rituximab & $375 \mathrm{mg} / \mathrm{m}^{2}$ intravenously weekly for $1-4$ doses & $\begin{array}{l}\text { Acute infusion reactions } \\
\text { Pulmonary fibrosis } \\
\text { Malignancy } \\
\text { Pneumocystis jiroveci pneumonia } \\
\text { Progressive multifocal } \\
\text { leukoencephalopathy }\end{array}$ \\
\hline
\end{tabular}

Children with frequently relapsing NS have somewhat better outcomes (72 and $36 \%$ sustained remission at 2 and 5 years, respectively) than children with steroid-dependent NS (40 and $24 \%$ sustained remission at 2 and 5 years) [36]. Older children (>7.5 years) appear to be more likely to achieve long-term remission than younger children ( $<3.8$ years) [38]. There is no difference in sustained remission rates between children treated with oral and intravenous (IV) cyclophosphamide at 12-
24 months of follow-up, and IV cyclophosphamide is generally reserved for children with demonstrated poor adherence.

Cyclophosphamide treatment can be associated with significant side effects. Gonadal toxicity may be seen more commonly in males than in females, particularly in those treated with cumulative doses $>200 \mathrm{mg} / \mathrm{kg}$ [36]. For this reason, a single course of therapy should be given with a maximum cumulative dose of $168 \mathrm{mg} / \mathrm{kg}(=2 \mathrm{mg} /$ $\mathrm{kg} /$ day $\times 12$ weeks). Fertility preservation strategies are 
available for treated patients [39]. Leukopenia and infection are other potentially serious side effects of cyclophosphamide therapy and occur in up to $32 \%$ of treated children [36]. White blood cell counts should be monitored along with dosing adjustments as necessary throughout treatment. Hair loss $(\sim 18 \%)$, hemorrhagic cystitis $(\sim 2.2 \%)$, and malignancy $(\sim 0.2 \%)$ are also potential complications of cyclophosphamide treatment.

\section{Calcineurin inhibitors}

Cyclosporine and tacrolimus are calcineurin inhibitors that are commonly used as immunosuppressive agents in solid organ transplantation. Calcineurin inhibitors (CNIs) inhibit T-cell activation and may be exerting their effect in nephrotic syndrome through this mechanism. Alternately, cyclosporine has been shown to directly target the podocyte and stabilize the actin cytoskeleton responsible for maintaining cell shape [40]. CNIs are recommended as first-line therapy for children with steroid-resistant NS and as steroid-sparing agents for children with frequently relapsing or steroid-dependent NS [20••]. Although the majority of studies in nephrotic syndrome have been performed with cyclosporine, tacrolimus appears to be equally efficacious [41, 42].

Children with steroid-resistant NS should receive a 6month trial of a CNI. Cyclosporine is administered at a starting dose of $4-5 \mathrm{mg} / \mathrm{kg} /$ day in two divided doses with monitoring of drug levels. Tacrolimus is administered at a starting dose of $0.1 \mathrm{mg} / \mathrm{kg} /$ day in two divided doses with monitoring of drug levels. Optimal initial and maintenance drug level targets are unknown, although trials have variably used troughs of $60-150 \mu \mathrm{g} /$ $\mathrm{L}$ for cyclosporine and $5-10 \mu \mathrm{g} / \mathrm{L}$ for tacrolimus. Of steroid-resistant children, 60-80\% will achieve either a complete or partial remission $(>50 \%$ reduction in proteinuria) after treatment with CNIs [43-45]. The optimal duration of treatment for steroid-resistant children who attain a remission with CNIs is unknown, and relapse is common after discontinuing the medication, leading to prolonged therapy in many children. However, many children can successfully stop CNIs and maintain remission. A recent study of children with steroidresistant NS treated successfully with cyclosporine for a median of 3 years found that $73 \%$ of children who stopped CSA had no further relapses of NS over a median follow-up of 9.7 years [45].

Children with frequently relapsing or steroiddependent NS can also be treated with CNIs at doses equivalent to those used for steroid-resistant NS. Of children with frequently relapsing or steroid dependent NS, 60-85\% will attain prolonged remission with this

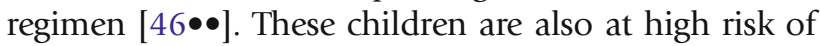
relapse after discontinuing the CNI with up to 85$100 \%$ of children experiencing a relapse after discontinuing CNI in some series [47, 48]. Two randomized controlled trials of cyclosporine vs. alkylating agents in children with frequently relapsing or steroiddependent NS showed no difference in risk of relapse as long as the child was taking cyclosporine [49, 50].

Side effects of cyclosporine include hypertension (10\%), gingival hypertrophy (32\%), elevated creatinine (6\%), and hypertrichosis (70\%) [51]. Tacrolimus causes significantly less gingival hypertrophy and hypertrichosis and may be preferred for children for whom cosmetic side effects are a concern, particularly teenage girls. Tacrolimus has the additional potential side effect of diabetes mellitus [52]. Children treated with CNIs can develop permanent renal interstitial fibrosis, with $11 \%$ of children treated for $<2$ years and $58 \%$ of children treated for $>2$ years demonstrating this finding on kidney biopsy [53]. For this reason, minimizing the dose of $\mathrm{CNI}$ and duration of therapy to maintain remission is recommended.

\section{Mycophenolate mofetil}

Mycophenolate mofetil (MMF) is a medication that suppresses the immune system through inhibition of B- and T-lymphocyte proliferation. Its mechanism of action in NS is also unknown, but presumed to work through immune suppression. It is gaining popularity as a treatment for NS due to its favorable side effect profile compared to CNIs, specifically its lack of renal toxicity.

The majority of studies using MMF have been performed in the frequently relapsing or steroid-dependent NS population. Treatment is typically started at $600 \mathrm{mg} /$ $\mathrm{m}^{2} /$ dose given twice daily and continued for at least 12 months [20••]. In studies of children with frequently relapsing NS, $64-80 \%$ of children remained in remission after 6-12 months of MMF therapy [46••, 54-56]. Similar to treatment with CNIs, children with frequently relapsing or steroid-dependent NS frequently relapse after discontinuing MMF, and prolonged therapy may be necessary.

MMF has also been used to treat steroid-resistant NS, although with somewhat less efficacy $[57,58]$. In a randomized multicenter trial, children and adults with steroid-resistant NS and FSGS on kidney biopsy were randomized to treatment with $\mathrm{MMF}+$ dexamethasone vs. cyclosporine. Partial or complete remission occurred 
in $46 \%$ of cyclosporine-treated patients and $33 \%$ of $\mathrm{MMF}+$ dexamethasone-treated patients after 12 months; however, the difference was not significant between the two arms of the study [58].

Side effects of MMF include stomach pain, diarrhea, leucopenia, and infection, although it is generally well tolerated [59]. MMF is teratogenic, so caution must be used when recommending this agent to women and girls of childbearing age [60]. One study has suggested that fewer relapses occur in children with higher mycophenolic acid exposure, although optimal trough levels and area under the curve measurements are unknown $[46 \bullet \bullet$.

\section{Rituximab}

Rituximab is a chimeric monoclonal antibody against CD20 on B cells that leads to B cell depletion after treatment. Rituximab may act in NS via alterations in B-cell/T-cell interactions leading to changes in cytokine secretion or co-stimulation. Alternately, rituximab may have a direct effect on podocyte structure and function as it has been found to bind directly to the sphingomyelin phosphodiesterase acid-like 3b (SMPDL-3b) protein on the surface of podocytes [61].

Rituximab has been found to be a useful drug to decrease relapse rates in children with frequently relapsing or steroid-dependent NS. Variable dosing regimens have been reported; however, 1-4-weekly doses of $375 \mathrm{mg} / \mathrm{m}^{2}$ is most commonly utilized. A short-term (3 month) randomized study demonstrated lower relapse rates from $48 \%$ in the standard of care arm to $18.5 \%$ in the rituximab treatment arm [62]. Nonrandomized trials have demonstrated 20-50\% 1-year remission rates in otherwise steroid- and CNI-dependent children, allowing for reduction in immunosuppressive therapy and improved linear growth $[63,64]$. A randomized controlled trial comparing 4-weekly doses of rituximab vs. placebo showed a longer relapse free period of 267 days in the rituximab-treated children compared to 101 days in the placebo group [65••]. However, all rituximab-treated children relapsed by 19 months. Finally, a second randomized controlled trial showed that children treated with a single dose of rituximab had lower prednisone requirement at 3 months and longer relapse-free survival than children treated with steroid taper [66]. Evidence does not currently support the use of rituximab in children with steroid-resistant NS, although case reports and case series have suggested up to $20 \%$ remission rates. In a single open-label randomized controlled trial, the addition of rituximab to baseline therapy of steroids and CNI did not reduce proteinuria at 3 months [67].

Use of rituximab in clinical practice is limited by concern for side effects. Approximately one third of treated children have acute infusion reactions consisting of fever, nausea/vomiting, diarrhea, rash, and bronchospasm [68]. Potentially serious and life-threatening side effects include pulmonary fibrosis, Pneumocystis jiroveci pneumonia, malignan$\mathrm{cy}$, and progressive multifocal leukoencephalopathy [69-71].

\section{Emerging therapies}

Adrenocorticotropic hormone (ACTH) was initially used in the 1950s to treat nephrotic syndrome and is the only US Food and Drug Administration-approved therapy for this indication [72]. ACTH fell out of favor for treatment of NS in the 1960s after the widespread availability of inexpensive oral steroids. Disadvantages of ACTH over oral steroids in children include the need to be injected and high cost. A current randomized trial of ACTH in children with frequently relapsing and steroid-dependent disease is ongoing and should shed light onto the efficacy and safety of ACTH in this population (NCT02132195).

Galactose is a monosaccharide sugar that binds to the focal sclerosis permeability factor in vivo and decreases its activity [73]. While some case reports have described remission after galactose treatment, a prospective study did not demonstrate any change in proteinuria after 16 weeks of therapy in seven children with steroid-resistant NS $[74,75]$. A recently completed phase II study (Novel Therapies for Resistant FSGS-FONT II) randomized seven adult and pediatric patients to galactose and found that three achieved a reduction in proteinuria by $50 \%$ at 26 weeks of therapy [76]. Further randomized controlled trials are necessary before galactose can be recommended for routine use. A second arm of the FONT II trial randomized seven pediatric and adult patients to treatment with adalimumab, an antiTNF antibody, and found no patients with a favorable response to treatment [76].

Abatacept (cytotoxic T-lymphocyte-associated antigen 4 immunoglobulin fusion protein) is a costimulatory inhibitor that targets B7-1 (CD80). While normally present on antigen-presenting cells, B7-1 has also been shown to be upregulated in podocytes in experimental nephrotic syndrome and possibly in a subset of patients with FSGS $[77,78]$. Abatacept is 
hypothesized to act in NS via stabilization of podocyte $\beta 1$-integrin activation and reduction of proteinuria. Abatacept treatment of four patients with recurrent nephrotic syndrome after transplant for FSGS and one patient with primary FSGS led to partial or complete remission in one case series; however, other reports have not demonstrated efficacy [78, 79]. Further clinical trials are required to determine which, if any, patients would benefit from treatment with abatacept.

\section{Conclusions}

In summary, a number of therapeutic options are available for treatment of children with NS. Careful consideration of potential complications should be discussed with families prior to prescribing treatments for NS. Further randomized controlled trials are necessary to determine which agents are most effective and to determine methods to predict medication response in individual children.

\section{Compliance with Ethical Standards}

\section{Conflict of interest}

Michelle Rheault has received researching funding from Amgen and Retrophin outside of the submitted work.

Human and animal rights and informed consent

This article does not contain any studies with human or animal subjects performed by any of the authors.

\section{References and Recommended Reading}

Papers of particular interest, published recently, have been highlighted as:

- Of importance

$\bullet \quad$ Of major importance

1. The primary nephrotic syndrome in children. Identification of patients with minimal change nephrotic syndrome from initial response to prednisone. A report of the International Study of Kidney Disease in Children. J Pediatr 1981;98:561-64.

2. Sadowski CE, Lovric $S$, Ashraf $S$, et al. A single-gene cause in $29.5 \%$ of cases of steroid-resistant nephrotic syndrome. J Am Soc Nephrol. 2015;26:1279-89.

3. Hinkes B, Wiggins RC, Gbadegesin R, et al. Positional cloning uncovers mutations in PLCE1 responsible for a nephrotic syndrome variant that may be reversible. Nat Genet. 2006;38:1397-405.

4. Tarshish P, Tobin JN, Bernstein J, Edelmann Jr CM. Prognostic significance of the early course of minimal change nephrotic syndrome: report of the International Study of Kidney Disease in Children. J Am Soc Nephrol. 1997;8:769-76.

5. Vernier RL, Farquhar MG, Brunson JG, Good RA. Chronic renal disease in children; correlation of clinical findings with morphologic characteristics seen by light and electron microscopy. AMA J Dis Child. 1958;96:306-43.

6. D'Agati VD, Fogo AB, Bruijn JA, Jennette JC. Pathologic classification of focal segmental glomerulosclerosis: a working proposal. Am J Kidney Dis. 2004;43:368-82.

7. Arneil GC, Lam CN. Long-term assessment of steroid therapy in childhood nephrosis. Lancet. 1966;2:819-21.

8. Hingorani SR, Weiss NS, Watkins SL. Predictors of peritonitis in children with nephrotic syndrome. Pediatr Nephrol. 2002;17:678-82.

9. Matsell DG, Wyatt RJ. The role of I and B in peritonitis associated with the nephrotic syndrome of childhood. Pediatr Res. 1993;34:84-8. 
10. McLean RH, Forsgren A, Bjorksten B, Kim Y, Quie PG, Michael AF. Decreased serum factor B concentration associated with decreased opsonization of Escherichia coli in the idiopathic nephrotic syndrome. Pediatr Res. 1977;11:910-6.

11. Anderson DC, York TL, Rose G, Smith CW. Assessment of serum factor $\mathrm{B}$, serum opsonins, granulocyte chemotaxis, and infection in nephrotic syndrome of children. J Infect Dis. 1979;140:1-11.

12. Ballow M, Kennedy 3rd TL, Gaudio KM, Siegel NJ, McLean RH. Serum hemolytic factor D values in children with steroid-responsive idiopathic nephrotic syndrome. J Pediatr. 1982;100:192-6.

13. Kerlin BA, Haworth K, Smoyer WE. Venous thromboembolism in pediatric nephrotic syndrome. Pediatr Nephrol 2013.

14. Kerlin BA, Ayoob R, Smoyer WE. Epidemiology and pathophysiology of nephrotic syndrome-associated thromboembolic disease. Clin J Am Soc Nephrol. 2012;7:513-20.

15. Ruth EM, Kemper MJ, Leumann EP, Laube GF, Neuhaus TJ. Children with steroid-sensitive nephrotic syndrome come of age: long-term outcome. J Pediatr. 2005; 147:202-7.

16. Shalhoub RJ. Pathogenesis of lipoid nephrosis: a disorder of T-cell function. Lancet. 1974;2:556-60.

17. Davin JC. The glomerular permeability factors in idiopathic nephrotic syndrome. Pediatr Nephrol 2015

18. Ransom RF, Lam NG, Hallett MA, Atkinson SJ, Smoyer WE. Glucocorticoids protect and enhance recovery of cultured murine podocytes via actin filament stabilization. Kidney Int. 2005;68:2473-83.

19. Xing CY, Saleem MA, Coward RJ, Ni L, Witherden IR, Mathieson PW. Direct effects of dexamethasone on human podocytes. Kidney Int. 2006;70:1038-45.

20.• Kidney Disease: Improving Global Outcomes (KDIGO) Glomerulonephritis Work Group. KDIGO Clinical Practice Guideline for Glomerulonephritis. Kidney Int, Suppl. 2012;2:139-274.

This is a comprehensive overview of evidence based treatment recommendations for children with steroid sensitive and steroid resistant nephrotic syndrome.

21. Hodson EM, Knight JF, Willis NS, Craig JC. Corticosteroid therapy for nephrotic syndrome in children. Cochrane Database Syst Rev 2005:CD001533.

22.• Sinha A, Saha A, Kumar M, et al. Extending initial prednisolone treatment in a randomized control trial from 3 to 6 months did not significantly influence the course of illness in children with steroid-sensitive nephrotic syndrome. Kidney Int. 2015;87:217-24.

This paper describes a randomized, placebo-controlled trial in children with their initial episode of nephrotic syndrome. They found that extending therapy from 3 to 6 months did not influence the course of illness or proportion of children with adverse effects.

23. Teeninga N, Kist-van Holthe JE, van Rijswijk N, et al. Extending prednisolone treatment does not reduce relapses in childhood nephrotic syndrome. J Am Soc Nephrol. 2013;24:149-59.
24. Alternate-day prednisone is more effective than intermittent prednisone in frequently relapsing nephrotic syndrome. A report of "Arbeitsgemeinschaft fur Padiatrische Nephrologie. Eur J Pediatr 1981;135:229237.

25. Short versus standard prednisone therapy for initial treatment of idiopathic nephrotic syndrome in children. Arbeitsgemeinschaft fur Padiatrische Nephrologie. Lancet 1988;1:380-383.

26. Pasini A, Aceto G, Ammenti A, et al. Best practice guidelines for idiopathic nephrotic syndrome: recommendations versus reality. Pediatr Nephrol. 2015;30:91-101.

27. MacHardy N, Miles PV, Massengill SF, et al. Management patterns of childhood-onset nephrotic syndrome. Pediatr Nephrol. 2009;24:2193-201.

28. Samuel S, Morgan CJ, Bitzan M, et al. Substantial practice variation exists in the management of childhood nephrotic syndrome. Pediatr Nephrol. 2013;28:2289-98.

29. Gipson DS, Massengill SF, Yao L, et al. Management of childhood onset nephrotic syndrome. Pediatrics. 2009;124:747-57.

30. Bagga A. Revised guidelines for management of steroid-sensitive nephrotic syndrome. Indian J Nephrol. 2008;18:31-9.

31. Srivastava RN, Vasudev AS, Bagga A, Sunderam KR. Long-term, low-dose prednisolone therapy in frequently relapsing nephrotic syndrome. Pediatr Nephrol. 1992;6:247-50.

32. Liu D, Ahmet $\mathrm{A}$, Ward $\mathrm{L}$, et al. A practical guide to the monitoring and management of the complications of systemic corticosteroid therapy. Allergy Asthma Clin Immunol. 2013;9:30.

33. Prospective, controlled trial of cyclophosphamide therapy in children with nephrotic syndrome. Report of the International study of Kidney Disease in Children. Lancet 1974;2:423-427.

34. Tarshish P, Tobin JN, Bernstein J, Edelmann Jr CM. Cyclophosphamide does not benefit patients with focal segmental glomerulosclerosis. A report of the International Study of Kidney Disease in Children. Pediatr Nephrol. 1996;10:590-3.

35. Plank C, Kalb V, Hinkes B, Hildebrandt F, Gefeller O, Rascher W. Arbeitsgemeinschaft fur Padiatrische N: Cyclosporin A is superior to cyclophosphamide in children with steroid-resistant nephrotic syndrome-a randomized controlled multicentre trial by the Arbeitsgemeinschaft fur Padiatrische Nephrologie. Pediatr Nephrol. 2008;23:1483-93.

36. Latta K, von Schnakenburg C, Ehrich JH. A metaanalysis of cytotoxic treatment for frequently relapsing nephrotic syndrome in children. Pediatr Nephrol. 2001;16:271-82.

37. Barratt TM, Soothill JF. Controlled trial of cyclophosphamide in steroid-sensitive relapsing nephrotic syndrome of childhood. Lancet. 1970;2:479-82. 
38. Azib S, Macher MA, Kwon T, et al. Cyclophosphamide in steroid-dependent nephrotic syndrome. Pediatr Nephrol. 2011;26:927-32.

39. Gajjar R, Miller SD, Meyers KE, Ginsberg JP. Fertility preservation in patients receiving cyclophosphamide therapy for renal disease. Pediatr Nephrol.

2015;30:1099-106.

40. Faul C, Donnelly M, Merscher-Gomez S, et al. The actin cytoskeleton of kidney podocytes is a direct target of the antiproteinuric effect of cyclosporine A. Nat Med. 2008;14:931-8.

41. Choudhry S, Bagga A, Hari P, Sharma S, Kalaivani M, Dinda A. Efficacy and safety of tacrolimus versus cyclosporine in children with steroid-resistant nephrotic syndrome: a randomized controlled trial. Am J Kidney Dis. 2009;53:760-9.

42. Gulati A, Sinha A, Gupta A, et al. Treatment with tacrolimus and prednisolone is preferable to intravenous cyclophosphamide as the initial therapy for children with steroid-resistant nephrotic syndrome. Kidney Int. 2012;82:1130-5.

43. Cattran DC, Appel GB, Hebert LA, et al. A randomized trial of cyclosporine in patients with steroid-resistant focal segmental glomerulosclerosis. North America Nephrotic Syndrome Study Group. Kidney Int. 1999;56:2220-6.

44. Ponticelli C, Rizzoni G, Edefonti A, et al. A randomized trial of cyclosporine in steroid-resistant idiopathic nephrotic syndrome. Kidney Int. 1993;43:1377-84.

45. Klaassen I, Ozgoren B, Sadowski CE, et al. Response to cyclosporine in steroid-resistant nephrotic syndrome: discontinuation is possible. Pediatr Nephrol. 2015;30:1477-83.

46.• Gellermann J, Weber L, Pape L, Tonshoff B, Hoyer P, Querfeld U. Gesellschaft fur Padiatrische N: Mycophenolate mofetil versus cyclosporin A in children with frequently relapsing nephrotic syndrome. J Am Soc Nephrol. 2013;24:1689-97.

This prospective open-label crossover study compared the efficacy of mycophenolate mofetil and cyclosporine in children with frequently relapsing nephrotic syndrome. They found no relapses in $85 \%$ of children treated with cyclosporine and $64 \%$ of children treated with mycophenolate.

47. Ishikura K, Yoshikawa N, Nakazato H, et al. Two-year follow-up of a prospective clinical trial of cyclosporine for frequently relapsing nephrotic syndrome in children. Clin J Am Soc Nephrol. 2012;7:1576-83.

48. Hulton SA, Neuhaus TJ, Dillon MJ, Barratt TM. Longterm cyclosporin A treatment of minimal-change nephrotic syndrome of childhood. Pediatr Nephrol. 1994;8:401-3.

49. Ponticelli C, Edefonti A, Ghio L, et al. Cyclosporin versus cyclophosphamide for patients with steroiddependent and frequently relapsing idiopathic nephrotic syndrome: a multicentre randomized controlled trial. Nephrol Dial Transplant. 1993;8:132632.

50. Niaudet P. Comparison of cyclosporin and chlorambucil in the treatment of steroid-dependent idiopathic nephrotic syndrome: a multicentre randomized controlled trial. The French Society of Paediatric Nephrology. Pediatr Nephrol. 1992;6:1-3.

51. El-Husseini A, El-Basuony F, Mahmoud I, et al. Longterm effects of cyclosporine in children with idiopathic nephrotic syndrome: a single-centre experience.

Nephrol Dial Transplant. 2005;20:2433-8.

52. Dittrich K, Knerr I, Rascher W, Dotsch J. Transient insulin-dependent diabetes mellitus in children with steroid-dependent idiopathic nephrotic syndrome during tacrolimus treatment. Pediatr Nephrol. 2006;21:958-61.

53. Iijima K, Hamahira K, Tanaka R, et al. Risk factors for cyclosporine-induced tubulointerstitial lesions in children with minimal change nephrotic syndrome. Kidney Int. 2002;61:1801-5.

54. Hogg RJ, Fitzgibbons L, Bruick J, et al. Mycophenolate mofetil in children with frequently relapsing nephrotic syndrome: a report from the Southwest Pediatric Nephrology Study Group. Clin J Am Soc Nephrol. 2006;1:1173-8.

55. Dorresteijn EM, Kist-van Holthe JE, Levtchenko EN, Nauta J, Hop WC, van der Heijden AJ. Mycophenolate mofetil versus cyclosporine for remission maintenance in nephrotic syndrome. Pediatr Nephrol. 2008;23:2013-20.

56. Baudouin V, Alberti C, Lapeyraque AL, et al. Mycophenolate mofetil for steroid-dependent nephrotic syndrome: a phase II Bayesian trial. Pediatr Nephrol. 2012;27:389-96.

57. Cattran DC, Wang MM, Appel G, Matalon A, Briggs W. Mycophenolate mofetil in the treatment of focal segmental glomerulosclerosis. Clin Nephrol. 2004;62:405-11.

58. Gipson DS, Trachtman H, Kaskel FJ, et al. Clinical trial of focal segmental glomerulosclerosis in children and young adults. Kidney Int. 2011;80:868-78.

59. Afzal K, Bagga A, Menon S, Hari P, Jordan SC. Treatment with mycophenolate mofetil and prednisolone for steroid-dependent nephrotic syndrome. Pediatr Nephrol. 2007;22:2059-65.

60. Hoeltzenbein M, Elefant E, Vial T, et al. Teratogenicity of mycophenolate confirmed in a prospective study of the European Network of Teratology Information Services. Am J Med Genet A. 2012;158A:588-96.

61. Fornoni A, Sageshima J, Wei C, et al. Rituximab targets podocytes in recurrent focal segmental glomerulosclerosis. Sci Transl Med. 2011;3:85ra46.

62. Ravani P, Magnasco A, Edefonti A, et al. Short-term effects of rituximab in children with steroid- and calcineurin-dependent nephrotic syndrome: a randomized controlled trial. Clin J Am Soc Nephrol. 2011;6:1308-15.

63. Ruggenenti P, Ruggiero B, Cravedi $P$, et al. Rituximab in steroid-dependent or frequently relapsing idiopathic nephrotic syndrome. J Am Soc Nephrol. 2014;25:85063.

64. Ravani P, Ponticelli A, Siciliano C, et al. Rituximab is a safe and effective long-term treatment for children with 
steroid and calcineurin inhibitor-dependent idiopathic nephrotic syndrome. Kidney Int. 2013;84:1025-33.

65.• Iijima K, Sako M, Nozu K, et al. Rituximab for childhood-onset, complicated, frequently relapsing nephrotic syndrome or steroid-dependent nephrotic syndrome: a multicentre, double-blind, randomised, placebo-controlled trial. Lancet. 2014;384:1273-81.

This randomized double-blind trial demonstrated that children with frequently relapsing or steroid dependent nephrotic syndrome treated with 4-weekly doses of rituximab had longer relapse-free survival compared to children who received placebo.

66. Ravani P, Rossi R, Bonanni A, Quinn RR, Sica F, Bodria M, Pasini A, Montini G, Edefonti A, Belingheri M, et al.: Rituximab in Children with Steroid-Dependent Nephrotic Syndrome: A Multicenter, Open-Label, Noninferiority, Randomized Controlled Trial. J Am Soc Nephrol 2015.

67. Magnasco A, Ravani P, Edefonti A, et al. Rituximab in children with resistant idiopathic nephrotic syndrome. J Am Soc Nephrol. 2012;23:1117-24.

68. Prytula A, Iijima K, Kamei $\mathrm{K}$, et al. Rituximab in refractory nephrotic syndrome. Pediatr Nephrol. 2010;25:461-8.

69. Chaumais MC, Garnier A, Chalard F, et al. Fatal pulmonary fibrosis after rituximab administration. Pediatr Nephrol. 2009;24:1753-5.

70. Deborska-Materkowska D, Kozinska-Przybyl O, Mikaszewska-Sokolewicz M, Durlik M. Fatal late-onset Pneumocystis pneumonia after rituximab: administration for posttransplantation recurrence of focal segmental glomerulosclerosis-case report. Transplant Proc. 2014;46:2908-11.
71. Kumar J, Shatat IF, Skversky AL, et al. Rituximab in post-transplant pediatric recurrent focal segmental glomerulosclerosis. Pediatr Nephrol. 2013;28:333-8.

72. Riley CM. Nephrotic syndrome. Effect of adenocorticotrophic hormone. Pediatrics. 1951;7:457-71.

73. Savin VJ, McCarthy ET, Sharma R, Charba D, Sharma $\mathrm{M}$. Galactose binds to focal segmental glomerulosclerosis permeability factor and inhibits its activity. Transl Res. 2008;151:288-92.

74. Sgambat K, Banks M, Moudgil A. Effect of galactose on glomerular permeability and proteinuria in steroidresistant nephrotic syndrome. Pediatr Nephrol. 2013;28:2131-5.

75. De Smet E, Rioux JP, Ammann H, Deziel C, Querin S. FSGS permeability factor-associated nephrotic syndrome: remission after oral galactose therapy. Nephrol Dial Transplant. 2009;24:2938-40.

76. Trachtman H, Vento S, Herreshoff E, et al. Efficacy of galactose and adalimumab in patients with resistant focal segmental glomerulosclerosis: report of the font clinical trial group. BMC Nephrol. 2015;16:111.

77. Reiser J, von Gersdorff G, Loos M, et al. Induction of B7-1 in podocytes is associated with nephrotic syndrome. J Clin Invest. 2004;113:1390-7.

78. Yu CC, Fornoni A, Weins A, et al. Abatacept in B7-1positive proteinuric kidney disease. $\mathrm{N}$ Engl J Med. 2013;369:2416-23.

79. Alachkar N, Carter-Monroe N, Reiser J. Abatacept in B71-positive proteinuric kidney disease. N Engl J Med. 2014;370:1263-4. 